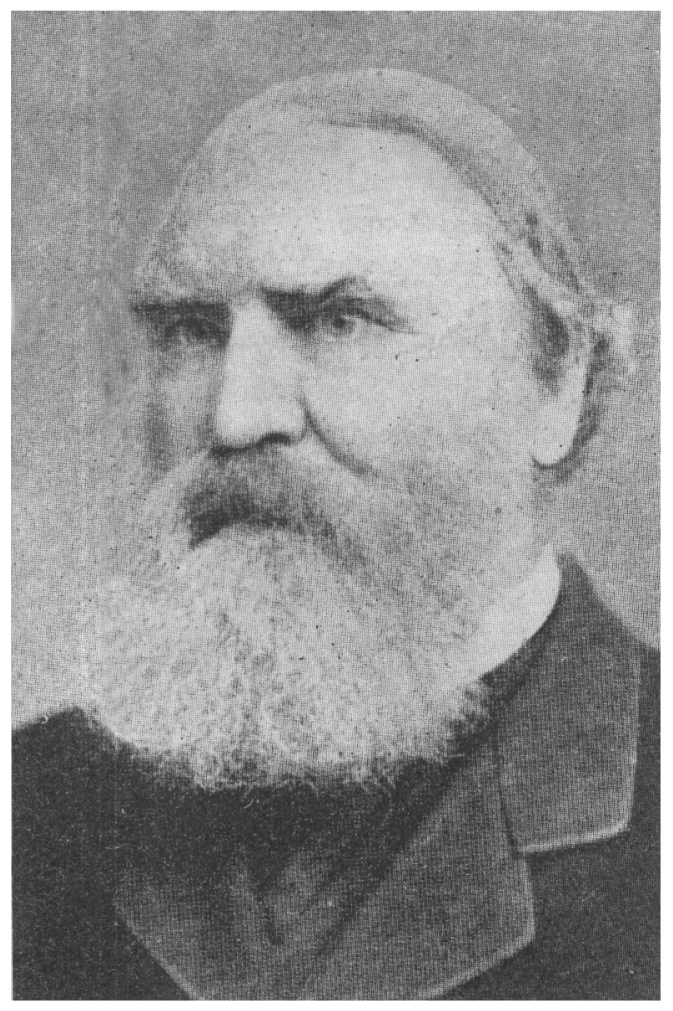

\section{FIFTY YEARS AGO}

FIFTY YEARS $A G O$, on the 31st January 1896, F. W. Brearey, the first secretary and driving force behind the formation of the Society and throughout its first thirty years, died at the age of eighty.

The following article, written by the late Major B. F. S. Baden-Powell, at that time Secretary of the Society, appeared in the first number of the Journal of the Aeronautical Society, in January 1897.

\title{
THE LATE MR. F. W. BREAREY
}

W HILE the world is waiting for the new developments which seem to broaden out in contemplation of the command of the atmosphere by man, so that he may be free to traverse it in every direction, we would remind those who would give honour where honour is due, not only to offer praise to the successful inventor, but also to those whose pioneering exertions have led to eventual success_for such it must be regarded. Prominent among these in our own country is the name of Frederick William Brearey, who seems very early in life to have been a dreamer of aerial dreams.

It may account for these youthful aspirations that his father was a friend of the late Sir George Cayley, of Stillingfleet, near Scarborough, the latter being the place of his birth in 1816. His father and sister were occasionally the witnesses of the experiments in flight made by the scientific baronet, and although Mr. Fred. Brearey does not remember any influence upon his mind resulting from overheard conversation, yet the idea seems possible. Although he says he remembers seeing Sir George at York, he never heard of his aerial experiments until after he arrived at manhood, and only then from his sister. Sir George Cayley's papers and experiments, published in the "Mechanic's Magazine" of that period, have since become to him and other students of aeronautics a storehouse of knowledge.

The time came when Mr. Brearey's aerial dreams began to take shape, but not until the year 1865 did he make any progress: 


\section{T H E L A T E M R. F. W. B R E A R E Y}

In the January of the next year the Aeronautical Society of Great Britain was launched from the House of the Duke of Argyll at Campden Hill. A nobleman of such acknowledged scientific attainments becoming President of the Society somewhat abated the ridicule of Mr. Brearey's friends, but it has accompanied him more or less as each attempt was reported a failure.

As soon as it became known that the Society was formed in Great Britain, there came plans and suggestions from all parts of the civilized world, with applications for the money which it was supposed that John Bull was anxious to lavish upon inventors, and from that time until now, nearly thirty years, the copies of letters, all in the handwriting of $\mathrm{Mr}$. Brearey, and the letters received, testify to the gratuitous labours of the Honorary Secretary.. The Société Française de Navigation Aérienne soon voted him their gold medal, and, as showing the effect which his papers, read at the meetings held at the Society of Arts, and magazine and newspaper articles, for the most part reprinted in other countries, had upon scientific minds, one of several letters spontaneously addressed to him will suffice. It was from the then President of the American Society of Civil Engineers, Mr. O. Chanute, dated from New York, February 3rd, 1882 :- "We are in this country aware of your longcontinued experiments and efforts to promote a solution of the problem of aerial navigation, and know that it is through your influence that the subject has been cleared of much rubbish, and placed upon a scientific and firm basis."

It was soon accepted by $\mathrm{Mr}$. Brearey as conviction, that aerial navigation could never be accomplished by balloons, however useful they might be in their own sphere, so that all his attention and experiments were directed to the mechanical means of attaining it. These were so suggestive and encouraging that in a lecture room he was able to show various forms of sustained flight over the heads of the audience, and although he has lectured in more than fifty cities and towns in England and Scotland, and liberated models of two or three pounds' weight, with a spread of wing of $12 \frac{1}{2} \mathrm{ft}$., he never caused an accident which created anything but amusement. Not so a lecturer at the Royal Polytechnic who, lecturing there upon the flight of one of Mr. Brearey's models, apologised for the absence of it upon one occasion "because the model had flown at a lady and the lady flew at him." The action of these models, of which he used to show more than thirty in his lectures, was very precarious, but occasionally their flight would surprise him. At Plymouth, for instance, one wing-flapped bird flew twice round the room, and returned to his hand on the platform, as if directed. At Truro, in a very large hall, a screwpropelled plane flew to the end of the hall, and, without touching the wall, turned round and got fixed on the gas fittings on the platform. At the Hartley Institute, Southampton, he liberated from his hand the model of an albatross, with wings of $12 \frac{1}{2} \mathrm{ft}$. in width, made of very slender material, both as to the shaft of the wing and the covering; so slender, indeed, that in holding it out ready for flight, the wings dropped on each side of him, so that no one would have thought flight possible, but the moment that action was imparted to those drooping wings, they stiffened out, and through the reflex action at the tip of the wing which effects propulsion, the model flew the whole length of the room, about $2 \mathrm{ft}$. above the heads of the audience, and, although rising at the end, just managed to clear the gallery. This was repeated with like result, in obedience to continued applause. With screw propelled planes he was equally successful, and it is on record how he suggested to Captain (now Lieut.-Colonel) Templer the means of sending information to a distance from a balloon. Mr. Brearey having supplied the apparatus of simple construction, Capt. Templer liberated it from a height, when it travelled back to 
Woolwich Arsenal against the wind, which carried away the balloon. Thus was conveyed a dead weight, the prerunner of the live weight conveyed in like manner by Herr Lilienthal's machine near Berlin-at that time a member of the Society. This successful experiment was recorded in the "Daily Telegraph," October 10th, 1879, and "Daily News," October 21st.

As Mr. Brearey has written a work, "The Atmosphere as a Medium of Travel," which awaits a publisher, I must abstain from much that I should like to chronicle, but I cannot forbear giving a few anecdotes. One of his correspondents, advocating the propulsion of balloons, thinks that it may be aciomplished thus: He would surround the balloon with compartments in which hawks can be located, confined by attachments to little leather breeches. When it is desired to propel the balloon, the aeronaut yells, and the hawks, liberated in this frightened manner, will lighten the balloon so that it will rise.

He even believes that they may be trained to pull altogether, and so hawk the balloon about the country. Another correspondent who, being an engineer, was supposed to understand the supporting power of surfaces when launched into the air from a height, seriously proposed the erection of towers at distances suitable to the effective gliding transmission of the surface. The passengers were to place themselves under this surface, and glide downwards to the next tower.

A lift would take them to the top while the apparatus would be hauled up for their reception, and away they would float off to the next tower, and so on, and so on.

These are a sample of some of the wild schemes of enthusiasts. Mr. Brearey has upon several occasions lost blood in the cause, and copiously, too, at the Alexandra Palace, when a screw-blade, revolving at a great velocity, produced by the great muscular effort he was exerting in turning a handle, flew off, and hitting him in the face, cut a portion of his nose off, at the same time cutting open his cheek. The nose was cleverly sewn on, but the after effect resulted in an operation by which the eye was barely saved. Again, when returning from the Crystal Palace, where for many days he had been in attendance, witnessing some interesting experiments in plane propulsion, a railway accident produced concussion of the brain, and confined him to his bed for many weeks. It was in connection with these experiments that the following ridiculous incident is related. Mr. Brearey had made an appointment to meet the Duke of Argyll, the late Duke of Sutherland, and the Earl of Dufferin. After they had spent some time in examining the steam-driven apparatus, said he, "We proceeded to the lower level exit to catch the train. On passing the cloak room the Earl started from us, saying he would be back directly, as he had left his coat there."

On attempting to pass the barrier, the ticket collector exclaimed to the Earl, who had the coat over his arm, "Holloa, where did you get that coat ?" The Earl was unaware that a ticket was attached to the coat, which had caught the inspector's attention, and caused him to look with suspicion upon the whole party. "Yes," said the Earl innocently, " there was no one in the cloak room so I took it."

This was too much for the inspector, who, casting a glance at us, said in an authoritative tone, "Has anyone else boned a coat ?" boned ?"

"Come with me," said the Duke of Argyll to the Earl. "What does he mean by 


\section{TH E L A T E M R. F. W. B R E A R E Y}

"Stole it," says the Earl.

As we reached the cloak room the attendant, who had left it for a short time, was just entering the room, thus confirming the Earl's statement. Of course, this was quite satisfactory. "But," says Mr. Brearey, "I shall not easily forget my indignation at the man's manner, nor my admiration at the suppression of any anger which must have been felt by the party. After they had departed I could not avoid saying to the inspector. "Do you know who that gentleman was that you accused of stealing a coat?"

"I neither know nor care," said the man carelessly.

"Well," I said, " he was the Earl of Dufferin, Governor-General of Canacla ; the taller of the two others was the Duke of Sutherland, and the other was the Duke of Argyll."

"Good God !" said the man, " you don't say so ?"

With respect to the ultimate issue of the late plane propelled experiments, Mr. Brearey, who-at least, theoretically-became possessed of as much knowledge as anyone in this kingdom, said that there were two systems by which success has been ascertained to be certain, so far as ascent is securable by mechanical means alone, viz.., Maxim's and Phillip's. The former answers to the prognostication of the Duke of Argyll, expressed when presiding over the first meeting of the Society in 1866.

"I think it quite certain that, if the air is ever to be navigated, it will not be by individual men flying; but that it is quite possible vessels may be invented which will carry a number of men, and the motive force of which will not be muscular action."

Mr. Maxim says that it is only for such dire purposes as war that his inventive genius has aimed at. This means heavy weights. Phillip's will come within the capacity of the pleasure seeker. Both have yet to come under control when set free in the air. Both inventors are members of the Society.

"Then," said Mr. Brearey, "will come the real test, and the real danger, but, that success will be ultimately attained, who that considers man's pluck, luck, and perseverance can doubt ?"

On January 31st, 1896, Frederick William Brearey suddenly and peacefully passed away. 